\title{
Diagnóstico ambiental de um câmpus universitário como estratégia para proposta de práticas sustentáveis
}

\author{
Environmental diagnosis of a university campus as a strategy for a sustainable \\ practices proposal
}

\begin{abstract}
Elaine Nolasco Ribeiro[a] (D), Raynan Lima Carneiro[a], Olga Porto da Silva Galdino[a], Pedro Henrique Vieira Duraes[a], Dulce Maria Sucena da Rocha[a], Maria Cristina de Oliveira[a]
\end{abstract}

Como citar: Ribeiro, E. N., Carneiro, R. L., Galdino, O. P. S., Duraes, P. H. V., Rocha, D. M. S. \& Oliveira, M. C. (2019). Diagnóstico ambiental de um câmpus universitário como estratégia para proposta de práticas sustentáveis. urbe. Revista Brasileira de Gestão Urbana, 11, e20190029. https://doi.org/10.1590/2175-3369.011.e20190029

\section{Resumo}

As universidades, direta ou indiretamente, causam impacto no ambiente através do consumo de água, energia, geração de resíduos e ocupação de áreas verdes. Este estudo teve por objetivo realizar um diagnóstico do consumo de água e energia; geração de resíduos e manejo de áreas verdes no câmpus da Faculdade UnB de Planaltina/Distrito Federal, para propor uma estratégia de gestão sustentável. Para tal, foram analisados os consumos de água e energia (período de 2006 a 2017), a caracterização quali-quantitativa dos resíduos sólidos (2015-2016) e estudo fitossociológico das áreas verdes do câmpus. Os resultados obtidos indicaram que os consumos de água e energia estão aumentando desde a inauguração do câmpus, em 2006, devido à ampliação do quadro de servidores, alunos e áreas edificadas. Dos resíduos sólidos produzidos, $67 \%$ são recicláveis. 0 estudo fitossociológico indicou alta diversidade biológica do Cerrado sentido restrito. Dentre as estratégias indicadas para gestão, indica-se a adoção de programas de uso eficiente da água e de energia elétrica e implantação da coleta seletiva com destinação da fração reciclável a cooperativas de catadores. Nas áreas verdes, recomenda-se sua preservação e conservação, além da expansão do câmpus em áreas mais degradadas do Cerrado sentido restrito, para reduzir a supressão da cobertura vegetal.

Palavras-chave: Câmpus universitário. Universidades sustentáveis. Resíduos. Água. Energia.

\begin{abstract}
Universities, directly or indirectly, have an impact on the environment through the consumption of water energy, generation of waste and occupation of green areas. This study aimed to perform a diagnosis of water and energy consumption, waste generation, and management of green areas in the UnB Planaltina Faculty/Federal District, to propose a sustainable management strategy. For that, water and energy consumption (2006 to 2017), qualitative and quantitative characterization of solid residues (2015-2016)
\end{abstract}

ENR é doutora em Biotecnologia Industrial, professora, e-mail: enolasco.unb@gmail.com

RLC é graduado em Gestão Ambiental, e-mail: raynanunb@gmail.com

OPSG é graduada em Ciências Naturais, e-mail: olgaportodasilva@gmail.com

PHVD é graduado em Gestão Ambiental, e-mail: pedrooowww@hotmail.com

DMSR é doutora em Biologia Vegetal, professora, e-mail: dmsrocha@yahoo.com.br

COM é doutora em Ciências Florestais, professora, e-mail: mcrisoliveira@unb.br 
and phytosociological study of the green areas of the campus were analyzed. The results indicate that water and energy consumption are increasing since the inauguration of the campus in 2006, due to the expansion of the number of servers, students and built areas. From the solid waste produced, 67\% is recyclable. The phytosociological study indicated high biological diversity of Cerrado restricted sense. Among the indicated strategies for management is the adoption of programs for the efficient use of water and energy, and the implementation of selective collection with destination of the recyclables to collectors cooperatives. In the green areas, it is recommended their preservation and conservation. Future expansions of the campus should occur in more degraded areas, such as Cerrado restricted sense, to reduce suppression of vegetation cover.

Keywords: University campus. Sustainable universities. Wastes. Water. Energy.

\section{Introdução}

As universidades desempenham várias atividades que causam impactos ambientais potencialmente significativos, que até recentemente foram amplamente ignorados em termos de responsabilidade social e ambiental. Uma instituição de ensino superior (IES) pode influenciar direta ou indiretamente o ambiente onde está localizada, devido ao seu tamanho e população (Gallardo et al. 2016; Lukman et al. 2009). Ao requerer serviços e infraestrutura na escala de uma pequena cidade (Geng et al. 2013; Gallardo et al. 2016; Tangwanichagapong et al. 2017), as universidades demandam acomodação, transporte, lojas, lazer, alimentação, gerenciamento de resíduos (Zhang et al. 2011; Vagnoni \& Cavicchi, 2015), abastecimento de água (Marinho et al. 2014) e energia (Petersen et al. 2015).

A sustentabilidade nas IES tornou-se uma temática de preocupação global para os seus gestores, como resultado dos impactos causados no ambiente local (Zhang et al. 2011; Gallardo et al. 2016). Além disso, as universidades devem assumir o compromisso de educar os alunos sobre o impacto que seu comportamento tem no meio ambiente e na sociedade (Mikulic \& Babina, 2009; Marinho et al. 2014) e desenvolver novas estratégias para a sua minimização.

Nas IES, as áreas para inclusão do desenvolvimento sustentável variam do ensino e pesquisa até o núcleo de gestão e marketing (Gallardo et al. 2016). Mundialmente, várias universidades têm se esforçado em implementar uma gestão ambiental sustentável no seu cotidiano (Brett et al. 2012; Zhao \& Zou, 2015; Gallardo et al. 2016; Tangwanichagapong et al. 2017). Um câmpus universitário sustentável deve ser economicamente equilibrado por meio da conservação dos recursos naturais e redução da geração de resíduos, a fim de promover a equidade e a justiça social em seus termos e exportar esses valores para a comunidade em níveis local, nacional e mundial (Gallardo et al. 2016; Tangwanichagapong et al. 2017).

No Brasil, as ações para a sustentabilidade nas universidades são restritas, podendo-se identificar projetos isolados de uso eficiente da água, economia de energia e gerenciamento de resíduos. Poucas universidades expressam uma política ambiental ou realizam amplos sistemas de gestão ambiental. As questões ambientais são predominantemente limitadas a pesquisas e cursos ou a disciplinas específicas (Marinho et al. 2014). No entanto, um arcabouço legal rege essa temática no Brasil.

No âmbito dos órgãos públicos federais, foi promulgado em 2006 o Decreto Federal n. 5.940, que instituiu a separação dos resíduos recicláveis descartados pelos órgãos e entidades da administração pública federal direta e indireta, na fonte geradora, e a sua destinação às associações e cooperativas dos catadores de materiais recicláveis (Brasil, 2006). Em fevereiro de 2015, o Ministério do Planejamento, Orçamento e Gestão publicou a Portaria de $n^{\circ} 23$, estabelecendo boas práticas de gestão e uso de energia elétrica e água nos órgãos e entidades da Administração Pública Federal, direta, autárquica e fundacional para o monitoramento do consumo (Brasil, 2015).

Ainda com o propósito de ordenar o gerenciamento dos resíduos sólidos no território brasileiro e proteger o meio ambiente, o principal marco legal relacionado à gestão de resíduos sólidos é a Lei n. 12.305/2010 (Brasil, 2010), que instituiu a Política Nacional de Resíduos Sólidos. Essa Lei aborda um 
dos maiores desafios, em termos ambientais, das políticas públicas voltadas à diminuição dos índices de poluição e degradação do meio ambiente. Assim, além da necessidade de as universidades brasileiras se tornarem sustentáveis, impulsionadas por uma tendência global, há também, legislações específicas que apontam esse rumo.

Nesse sentido, o primeiro passo para implantar uma gestão ambiental eficiente e direcionada para a sustentabilidade em um câmpus universitário é avaliar o uso dos recursos naturais e sua produção de resíduos. 0 objetivo do presente estudo foi realizar um diagnóstico do consumo de água e energia, produção e gerenciamento de resíduos e o manejo de áreas verdes no câmpus da Faculdade UnB de Planaltina (FUP), no Distrito Federal, para obter informações necessárias ao desenvolvimento de uma estratégia de gestão ambiental, compatível com a legislação nacional e mais sustentável.

\section{Metodologia}

\section{Área de estudo}

O câmpus da Faculdade UnB Planaltina (FUP) é um dos três novos campi da Universidade de Brasília, distando $40 \mathrm{~km}$ do câmpus Darcy Ribeiro, o mais antigo da universidade. As atividades acadêmicas foram iniciadas em 2006 com apenas dois cursos de graduação. Atualmente, a FUP possui quatro cursos de graduação e cinco cursos de pós-graduação, atendendo uma população de 1.355 alunos, 110 professores e 137 servidores distribuídos nas áreas administrativas e de demais serviços, conforme levantamento feito no setor de recursos humanos do câmpus.

A FUP possui área total $301.847,06 \mathrm{~m}^{2}$ (30,18ha), com área construída de aproximadamente $12.557,51 \mathrm{~m}^{2}$ (0,12ha). A estrutura física do câmpus é composta por quatro edificações, conforme demonstrado na Figura 1: a) Unidade de Ensino e Pesquisa (UEP), que abriga o setor administrativo, salas de professores, laboratórios e pós-graduação; b) Unidade Acadêmica (UAC), que abriga as salas de aula da graduação e seus respectivos laboratórios de química e biologia, além da cantina, biblioteca e um auditório; c) Restaurante Universitário (RU) e quadra de esportes; d) Alojamento estudantil, que comporta aproximadamente 100 pessoas; possui infraestrutura de dormitórios, cozinhas, lavanderias e banheiros. Ainda há dois estacionamentos: um em frente ao prédio da UEP e outro em frente do prédio da UAC. 


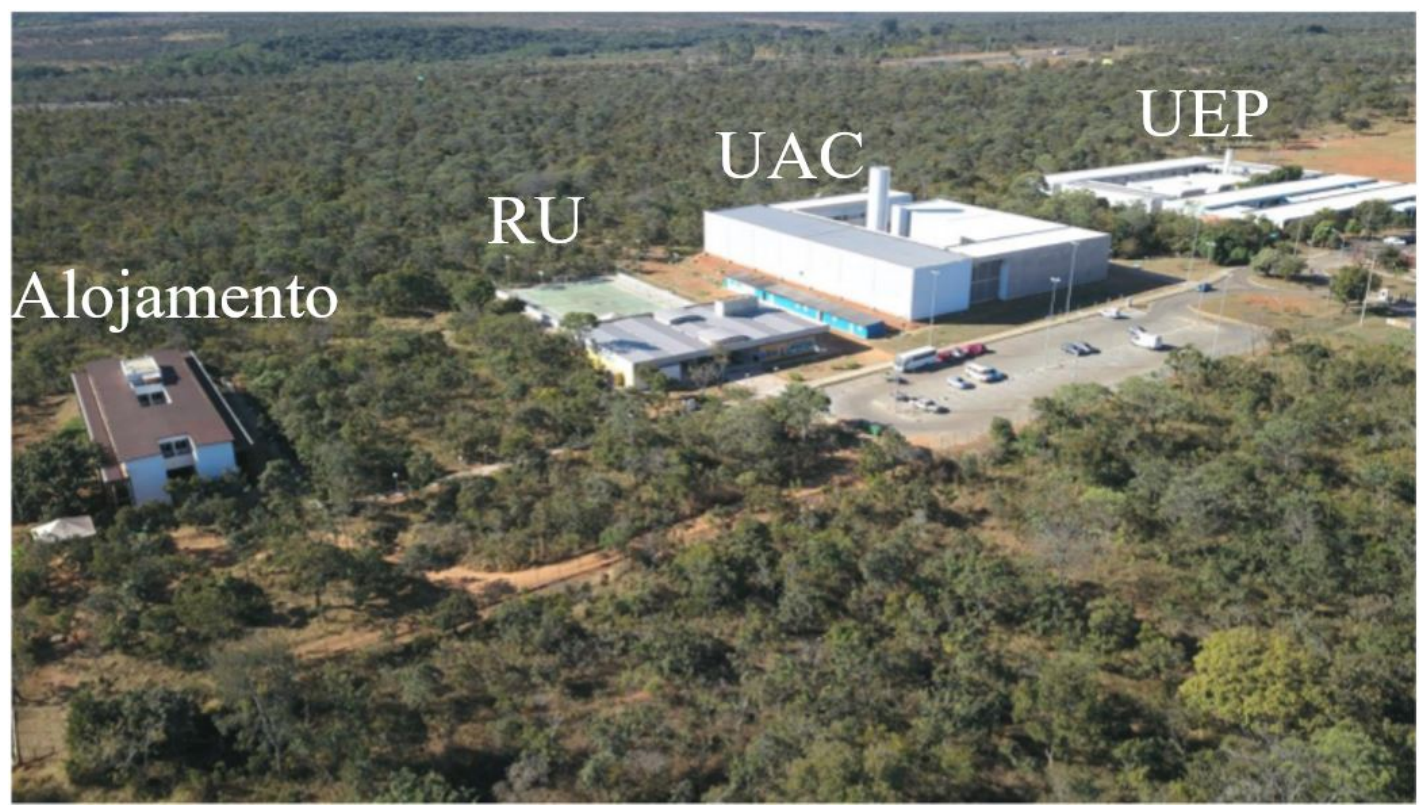

Figura 1 - Localização da Faculdade UnB Planaltina (FUP) com a distribuição das edificações do câmpus. Legenda: Unidade Acadêmica (UAC); Unidade Ensino e Pesquisa (UEP); Alojamento estudantil; Restaurante Universitário (RU). Fonte: Couto-Júnior (2017).

A universidade fica aberta de segunda-feira a sábado, exceto períodos de feriados e recesso entre Natal e Ano Novo. Aos domingos, o acesso é restrito à biblioteca, ao alojamento estudantil e ao RU. O primeiro semestre letivo tem início no mês de março e termina em julho. 0 segundo semestre inicia-se em agosto e termina em dezembro. $\mathrm{O}$ RU funciona de segunda-feira a domingo. Nos períodos de férias e feriados, a única cantina existente permanece fechada.

\section{Os agentes consumidores}

Para estimativa dos agentes consumidores, o número de servidores e alunos que frequentam a FUP foi obtido no setor de recursos humanos e divisão de registros acadêmicos, respectivamente, considerando-se para análise o período de 2006 a 2017. A população correspondente àqueles que acessam a instituição eventualmente, como em eventos, não foi considerada por ser difícil a sua determinação.

\section{Consumo de água}

Realizado identificando-se os consumos mensais no período de 2006 a 2017, junto à prefeitura universitária e à Companhia de Saneamento Ambiental do Distrito Federal (CAESB). A identificação das médias de consumo na FUP foi obtida através da análise das séries históricas de consumo de água registradas por dois hidrômetros. 0 hidrômetro C01N000109 (hidrômetro 1) atende o prédio da UEP, e o hidrômetro F03N000319 (hidrômetro 2) atende os prédios da UAC, RU e alojamento. A identificação dos pontos de consumo de água foi realizada através das plantas baixas dos prédios e checagem in loco. A determinação do índice de consumo de água $\left(\mathrm{IC}_{\mathrm{A}}\right)$ foi feita a partir da Equação 1. Esse dado permite a comparação de dados com outras instituições de porte semelhante e identificação dos excessos de consumo.

$$
I C_{A}=\text { volume de água consumido (periodo)/agentes consumidores (período) }
$$




\section{Geração de resíduos sólidos}

Os estudos sobre os resíduos sólidos produzidos no câmpus da FUP foram realizados em três etapas: (1) identificação do sistema de gerenciamento adotado no câmpus, (2) caracterização quantitativa e qualitativa dos resíduos gerados e (3) avaliação do potencial de reciclagem dos resíduos produzidos no câmpus. Para conhecer o sistema de gerenciamento de resíduos da FUP, foram realizadas entrevistas não estruturadas com os funcionários encarregados da limpeza, com o assistente da direção, técnicos dos laboratórios e com funcionários do RU, para identificação dos tipos de resíduos gerados e da forma de gerenciamento adotada.

A quantificação dos resíduos produzidos nos prédios da UAC, UEP e alojamento foi obtida pela sua pesagem durante quatro semanas consecutivas, de segunda a sexta-feira, no mês de novembro de 2015. Os resíduos produzidos em cada prédio foram acumulados por $24 \mathrm{~h}$ para pesagem em cada unidade geradora, sendo utilizadas duas balanças digitais, uma com capacidade de até $100 \mathrm{~kg}$ e outra de $500 \mathrm{~kg}$. Para se obter o índice de geração per capita, que reflete a quantidade de resíduos gerados por pessoa, foi utilizada a Equação 2, descrita a seguir:

$$
\text { Geração per capita }(\mathrm{kg} / \mathrm{hab} .)=\frac{\text { Peso total lixo diário }(\mathrm{kg})}{\text { População frequentadora }(\mathrm{hab})}
$$

Apesar de o câmpus estar em atividade desde o ano de 2006, o RU só foi inaugurado no final de 2015. Os resíduos gerados no RU foram pesados durante uma semana, de segunda a sexta-feira, no mês de junho de 2016; a metodologia desenvolvida para esta etapa foi similar à realizada para os demais prédios.

A caracterização dos resíduos foi realizada em três etapas: 1aㅡ novembro de 2015, resíduos produzidos nos prédios da UAC e UEP; $2^{\text {a }}$ ) junho de 2016, resíduos produzidos no RU; $3^{a}$ ) novembro de 2016, resíduos produzidos nos prédios da UAC e UEP. Antes da caracterização, os resíduos gerados em cada prédio foram estocados por 24 horas, e o procedimento realizado conforme recomendado por Instituto Brasileiro de Administração Municipal (IBAM, 2001).

No dia da caracterização, os sacos contendo os resíduos de cada prédio foram pesados individualmente e depois rasgados em cima de uma lona plástica para a separação das frações: papel, papelão, plástico, lata, embalagem tetrapak e isopor. Como a quantidade de resíduos era relativamente pequena, os resíduos foram totalmente caracterizados sem utilização de técnicas de amostragem, exceto no prédio da UAC, para o qual se empregou a técnica de quarteamento recomendada por Instituto Brasileiro de Administração Municipal (IBAM, 2001). Para determinação do percentual de cada um dos componentes identificados, foi utilizada a Equação 3:

Material $(\%)=\frac{\text { Peso da fração do material }(\mathrm{kg})}{\text { Peso total da amostra }(\mathrm{kg})} \times 100$

\section{Consumo de energia}

O consumo global de energia na FUP foi obtido a partir das faturas emitidas pela concessionária, abrangendo o período entre 2007 e 2017. O indicador escolhido para o diagnóstico energético foi o consumo mensal por área construída em $\mathrm{m}^{2}$, conforme sugerido pela Portaria 23 do Ministério do Planejamento (Brasil, 2015), Equação 4.

Índice de Consumo $\left(I C_{E E}\right)=\frac{\text { Consumo de energia elétrica }(\mathrm{kWh} / \mathrm{mê})}{\text { Área construída }\left(\mathrm{m}^{2}\right)}$ 


\section{Manejo de áreas verdes}

Como parte de um dos projetos de pesquisa de longo prazo e com o objetivo de conhecer as principais espécies da área de reserva da FUP, foi realizado um levantamento da vegetação arbórea. 0 método empregado para este inventário seguiu o mesmo protocolo adotado por Felfili et al. (1994). Desta forma, foram estabelecidas dez parcelas permanentes de $20 \mathrm{~m}$ x $50 \mathrm{~m}$ aleatorizadas, perfazendo 1 ha de área amostrada. Todos os indivíduos lenhosos com diâmetro $\geq 5 \mathrm{~cm}$ foram amostrados. De cada indivíduo foram anotados a altura e o diâmetro a $30 \mathrm{~cm}$ do solo. Com os dados coletados foram calculados parâmetros fitossociológicos, tais como Área Basal Total, Índice de Valor de Importância e Índice de Diversidade de Shannon.

\section{Resultados e discussão}

\section{Diagnóstico do consumo de água}

Conforme a Figura 2, desde a inauguração da FUP em 2006, o número de integrantes da comunidade acadêmica aumentou nove vezes até 2012, reflexo da abertura de quatro cursos de graduação e cinco cursos de pós-graduação. A partir de 2012, observa-se uma tendência à estabilização do crescimento populacional.

A série histórica do consumo de água no câmpus compreende o período de 2006 a 2017, Figura 3. De 2006 até 2014, observa-se uma elevação no consumo de água no câmpus, que está relacionado ao aumento da população acadêmica e fase de consolidação do câmpus. Pontualmente, observa-se uma queda do consumo de água no ano de 2012, que pode ser justificada pela ocorrência de uma greve geral de servidores e professores durante os meses de maio a outubro, ocasionando o esvaziamento do câmpus e prorrogação do segundo semestre letivo de 2012 até março de 2013. No ano de 2014, ocorreu um pico no consumo de água, sendo os meses de junho a outubro os de maior consumo. Em 2015, houve uma queda no consumo de água, pois em uma decisão conjunta da direção do câmpus com a assessoria ambiental, optou-se por reduzir a frequência de rega dos jardins e áreas verdes, além de evitar a lavagem de pátios e corredores.



Figura 2 - Crescimento populacional na FUP. Fonte: autores (2019). 


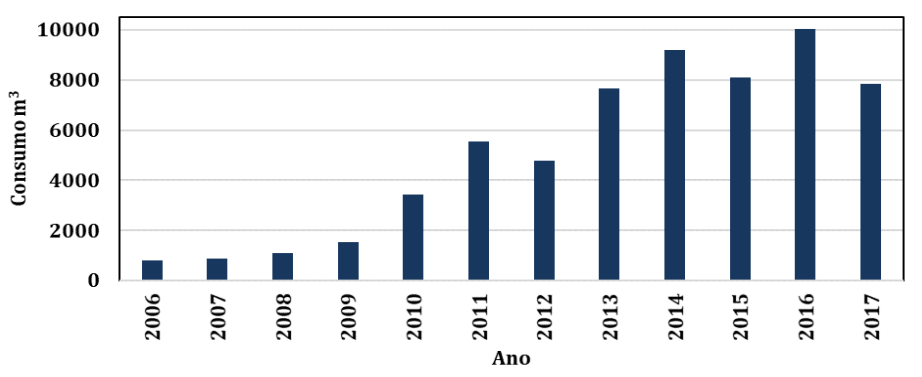

Figura 3 - Consumo acumulado de água. Fonte: autores (2019).

Outras medidas para uso eficiente da água foram adotadas, como a restrição no uso de mangueiras para limpeza de áreas comuns e de aspersores para a rega de áreas verdes. Em 2016, semelhantemente a 2014, o consumo também aumentou entre os meses de maio e outubro, chegando a $10.000 \mathrm{~m}^{3}$. A elevação do consumo de água nesse período se relaciona com a época da seca no Distrito Federal, que começa em maio e vai até o final de outubro, quando tem início a temporada de chuvas. Logo, observa-se uma tendência de maior consumo de água do meio para o final do período, quando os efeitos da seca são mais sentidos e quando normalmente se gasta mais água para a rega de áreas verdes do câmpus.

De acordo com Santana \& Kiperstok (2010), em prédios públicos, como o da FUP, o consumo de água está intrinsecamente relacionado à tipologia das edificações, como locais de usos específicos (laboratórios, banheiros, restaurantes, cantinas, alojamentos, jardins, dentre outros), à quantidade de pessoas que frequentam o local, ao processo construtivo das suas instalações hidráulicas, defeitos e condições de manutenção destas e aos modos de usos da água, como a limpeza das áreas comuns.

Objetivando fazer uma avaliação mais pontual do consumo de água no câmpus, é apresentada na Figura 4 a evolução do consumo por hidrômetro instalado. Nota-se que, a partir de 2011, após a inauguração da UAC e do prédio do alojamento estudantil, locais que concentram o maior número de estudantes da FUP, houve um aumento crescente do consumo de água medido pelo hidrômetro 2. A partir de 2013, o consumo do hidrômetro 2 superou o 1, reforçado pelo início das atividades do RU em 2015.



Figura 4 - Consumo anual de água por hidrômetro na FUP. Fonte: autores (2019).

Esses dados demonstram que as demandas de água no câmpus estão relacionadas às atividades que envolvem os estudantes de graduação, como as aulas, a alimentação e a sua permanência ao longo do dia na instituição. Por outro lado, do ano de 2015 em diante, observa-se uma tendência de queda na demanda de água no prédio mais antigo, a UEP, que tem o consumo medido pelo hidrômetro 1. Em 2016 e 2017, as diferenças de consumo entre o hidrômetro 1 e 2 se acentuaram, indicando que o conjunto de prédios com consumo medido pelo hidrômetro 2 demanda maiores quantidades de água. Isso também está relacionado ao fato de o número de aulas de graduação no prédio UEP ter diminuído ao longo dos anos, por causa da maior utilização do prédio da UAC.

Foram contabilizadas na FUP 352 fontes consumidoras de água distribuídas nos edifícios que compõem o câmpus. São 34 sanitários, 17 laboratórios com pontos de fornecimento de água, 
01 restaurante e 01 lanchonete, 03 cozinhas e 02 copas, 01 alojamento estudantil, além dos jardins. Os sanitários estão distribuídos de forma agrupada nos prédios da UEP, UAC, no alojamento estudantil e $\mathrm{RU}$, sendo abastecidos com água fria e quente (esta última somente em alguns banheiros que contêm chuveiro).

Dentre as ações que podem ser adotadas para redução do consumo de água, está a regulagem dos equipamentos hidrossanitários, ação que reduz o consumo em até 20\% (Sousa et al. 2011), otimização da rega de áreas verdes, já adotado, e fontes alternativas de água. No alojamento estudantil, prédio mais recente do câmpus, já existe um sistema de aproveitamento de água da chuva, mas que atualmente se encontra inativo.

Os IC A $_{\mathrm{A}}$ para o período de 2006 e 2017 são apresentados na Figura 5. De acordo com Menegassi (2012), o consumo médio de água em prédios públicos é de 50,0 litros/funcionário.dia. Um estudo realizado por Marinho et al. (2014) na Universidade Federal da Bahia (UFBA) identificou que o consumo mensal de água no ano de 2011 foi de $26.900 \mathrm{~m}^{3}$, e o IC de $26.8 \mathrm{~L} /$ pessoa.dia. Na FUP, o índice de consumo mais elevado foi em 2014, chegando próximo a $25 \mathrm{~L}$ /pessoa.dia. A UFBA possui 35.000 alunos e mais de 100 prédios no câmpus em questão, apesar de o índice de consumo ser calculado por usuário.dia, uma estrutura maior tende a consumir mais água. No entanto, o que se observa é que a FUP, com dimensões bem menores, tem um índice de consumo próximo ao da UFBA, o que é bastante preocupante.

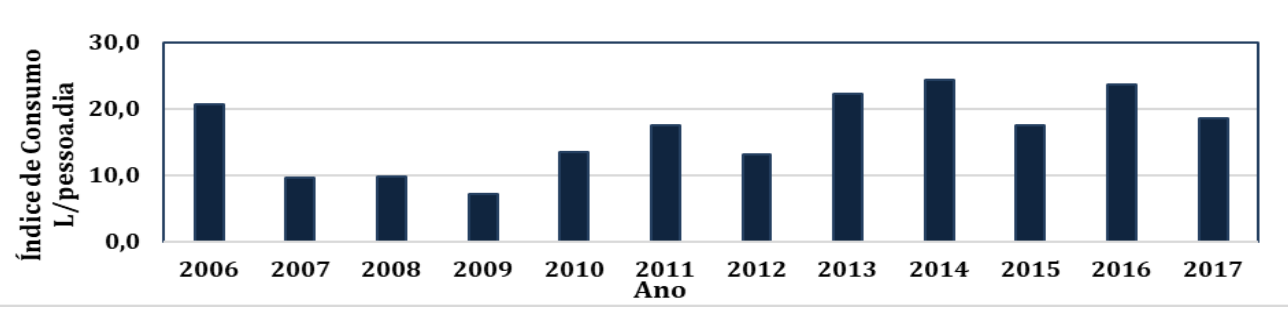

Figura 5 - Índices de consumo na FUP (L/pessoa.dia) entre os anos de 2006-2017. Fonte: autores (2019).

O elevado $\mathrm{IC}_{\mathrm{A}}$ no ano de 2006 pode ser explicado devido ao período de construção da Unidade de Ensino e Administração (UEA). A partir do ano de 2010, observa-se uma elevação do $\mathrm{IC}_{\mathrm{A}}$ de forma geral, o que pode estar relacionado ao desenvolvimento de novas atividades de ensino e pesquisa no câmpus.

\section{Diagnóstico da geração de resíduos}

\section{Análise quantitativa dos resíduos}

De acordo com a Figura 6, o volume de resíduos gerados pela FUP ao longo de um mês é de 3.794kg, e diariamente são produzidos $148 \mathrm{~kg}$ de resíduos (considerando-se seis dias úteis por semana). 0 restaurante universitário é o maior gerador de resíduos, seguido pelo alojamento, UEP e UAC. No RU são servidas em torno de 600 refeições por dia, divididas em café da manhã, almoço e jantar, de segunda a sábado. A geração de resíduos pelo RU chega a ser 4,5 vezes maior que os prédios da UEP e UAC juntos, demonstrando assim que esse local é um alvo para se trabalhar a redução da geração de resíduos e a sua destinação final ambientalmente adequada.

No estudo realizado por Gallardo et al. (2016) ao avaliarem os resíduos gerados na Universidade Jaime I (UJI), localizada em Castellón de La Plana, Espanha, os autores observaram que a cantina era o local com maior geração de resíduos. Por outro lado, De Vega et al. (2008), ao caracterizarem os resíduos gerados no câmpus Mexicali I da Universidade Autônoma de Baja Califórnia (UABC), relataram que 53,5\% dos resíduos gerados no câmpus eram provenientes dos prédios que abrigavam os setores administrativos, salas de aula e laboratórios. A partir desses estudos, observa-se que o local de maior geração de resíduos em um câmpus pode ser bastante variável. 
Os resultados apresentados na Figura 7 indicam que 67\% dos resíduos da FUP podem ser considerados recicláveis ou potencialmente recicláveis, conforme a existência de cadeias de reciclagem locais ou valorização destes para a comercialização. Os 33\% restantes são considerados resíduos orgânicos e rejeitos, sendo a fração orgânica passível de ser destinada para compostagem. Na FUP, o grande volume de material orgânico é decorrente do do RU, tanto na preparação das refeições quanto no que é desperdiçado pelos usuários, correspondendo em média a $30 \mathrm{~kg}$ de resíduos por dia.

Gallardo et al. (2016) detectaram que 46\% dos resíduos gerados no câmpus da Universidade Jaime I (UJI), na Espanha, são constituídos por matéria orgânica. Fagnani \& Guimarães (2017) identificaram que $35 \%$ dos resíduos gerados em toda a Escola de Engenharia Civil, Arquitetura e Design Urbano da Unicamp, São Paulo, Brasil, correspondiam a fração orgânica. Logo, observa-se que o percentual de resíduos orgânicos encontrados na FUP fica próximo ao de outras universidades, além de notar-se que a fração reciclável prevalece sobre a orgânica.

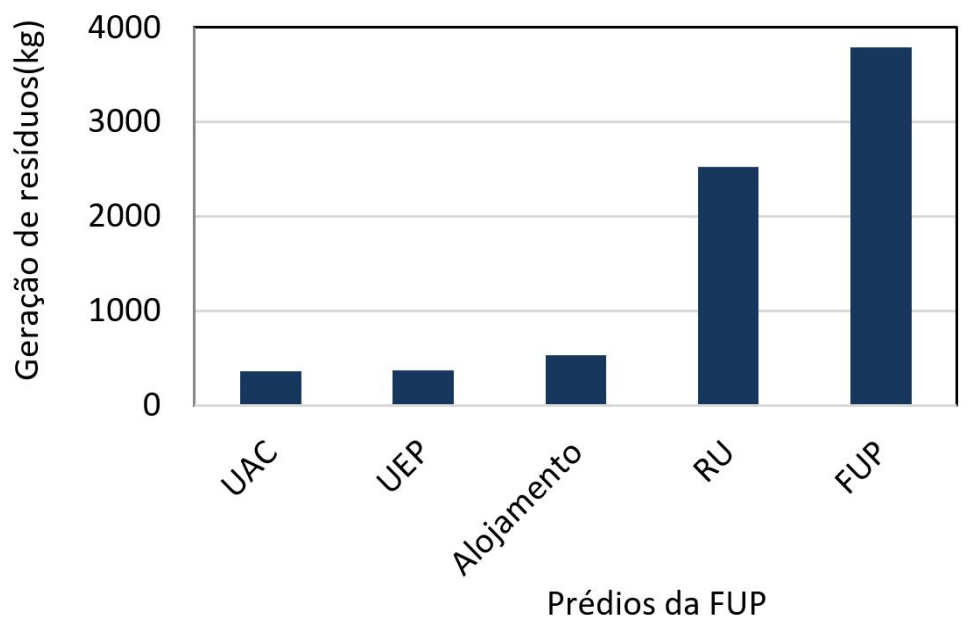

Figura 6 - Geração de resíduos por prédio da FUP. Fonte: autores (2019).

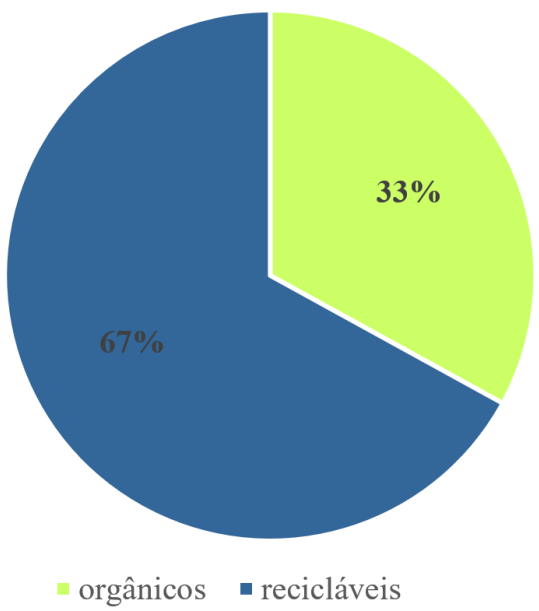

Figura 7 - Percentual de geração de resíduos orgânicos e recicláveis na FUP. Fonte: autores (2019).

Na FUP, a taxa de geração per capita é de $0,092 \mathrm{~kg}$, ou seja, 92g/pessoa.dia. No estudo conduzido por Morales (2012) na Universidade Iberoamericana, a geração per capita foi de 330g/pessoa.dia, valor bem superior ao da FUP. Okeniyi \& Anwan (2012) encontraram uma taxa de geração per capita de $60,50 \mathrm{~g} /$ pessoa.dia para a Universidade Covenant, valor um pouco abaixo ao da FUP. Logo, observa-se que a determinação da taxa de geração per capita é importante, porém reflete o padrão de consumo de cada local, do poder aquisitivo dos usuários e de hábitos culturais de cada comunidade. 


\section{Composição gravimétrica}

Conhecer as características dos resíduos é de fundamental importância para definir a melhor estratégia de destinação final, como o potencial para reciclagem. Os dados referentes à composição gravimétrica dos resíduos gerados na FUP são apresentados na Figura 8. Dentre os materiais recicláveis, o plástico, papel e o papelão são as frações mais representativas, com potencial de recuperação para a reciclagem. Os locais com maior quantidade de resíduos recicláveis são os prédios administrativo (UEP) e o de salas de aula (UAC).

Os resultados obtidos na FUP são comparáveis ao de Gallardo et al. (2016), no câmpus da Universidade Jaime I (UJI), na Espanha, na qual os resíduos gerados em maior quantidade e com potencial para reciclagem são o plástico $(12,50 \%)$ e o papel $(4,08 \%)$.

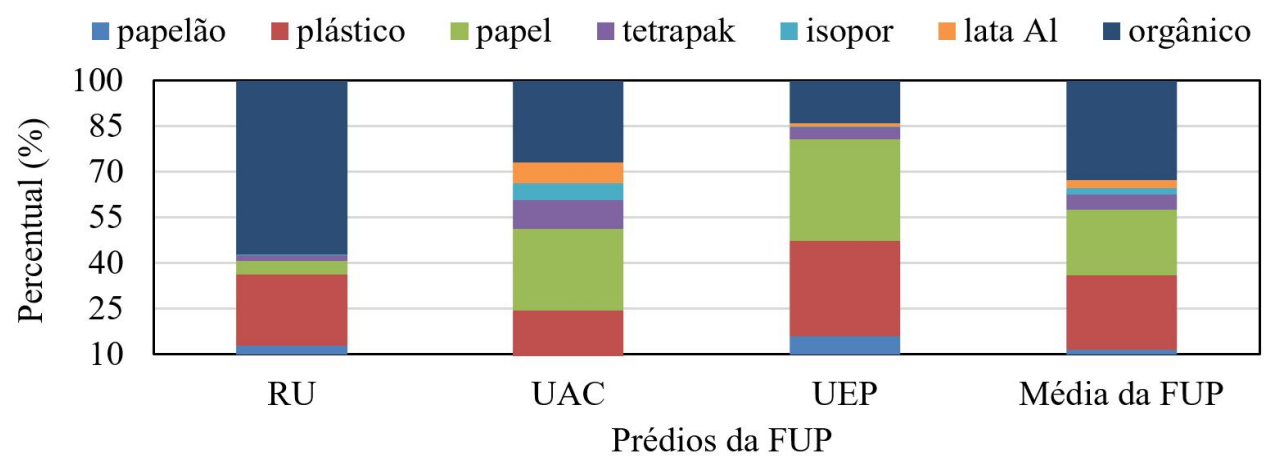

Figura 8 - Composição gravimétrica (\%) dos resíduos gerados na FUP. Fonte: autores (2019).

\section{Gerenciamento de resíduos}

Na UnB, o gerenciamento dos resíduos perigosos produzidos em todos os câmpus é realizado através do programa RESQUI, coordenado pela Comissão de Gerenciamento, Tratamento e Destinação de Resíduos Perigosos da Universidade de Brasília (GRP-UnB). Portanto, na FUP, a atribuição dos geradores de resíduos perigosos é apenas separar e acondicionar os resíduos de forma adequada para a coleta pelos agentes do programa. Os resíduos comuns produzidos no câmpus são acondicionados, recolhidos pelos funcionários da limpeza e destinados ao serviço de limpeza urbana (SLU), orgânicos/rejeitos, e os recicláveis a uma cooperativa de catadores.

\section{Diagnóstico do consumo de energia}

A FUP é alimentada pela Companhia Energética de Brasília (CEB) em tensão de 13.8kV. 0 ponto de entrega é a subestação do câmpus, que transforma essa tensão em 380 volts para ser distribuída às cabinas primárias do câmpus. Os dados referentes ao consumo de energia elétrica na FUP, para o período de 2007 e 2017, são apresentados na Figura 9, indicando que o consumo anual aumentou em cinco vezes, com significante alteração de consumo no ano de 2013 em diante.

Em termos monetários, apenas no ano de 2017 foram gastos aproximadamente $\mathrm{R} \$ 357.000,00$ reais com o pagamento das contas de energia elétrica. Desde que a FUP foi inaugurada em 2006 e os cursos de graduação e pós-graduação tiveram início, o aumento da demanda de carga elétrica já era esperado, tendo em vista o crescimento do câmpus em número de usuários e de áreas construídas, além do desenvolvimento de novas atividades acadêmicas. 


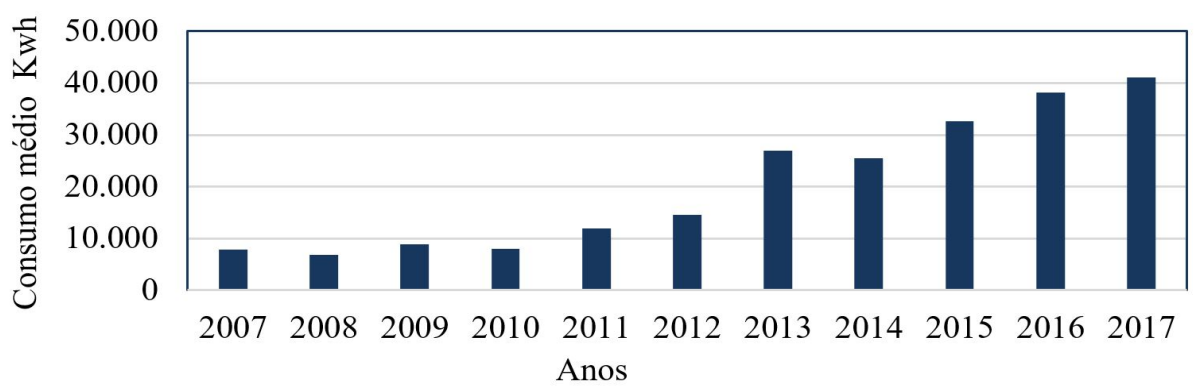

Figura 9 - Consumo médio anual de energia elétrica na FUP. Fonte: autores (2019).

No Brasil, os dados sobre monitoramento do consumo de energia elétrica em universidades são um tanto escassos. Na maior universidade pública do Brasil, a Universidade de São Paulo (USP), a média de consumo mensal de energia elétrica é de 12GWh. Seu maior câmpus, a Cidade Universitária Armando de Salles Oliveira (CUASO), responde por 48\% do consumo, e o câmpus de Lorena, o menor consumo, 1,36\% (Saidel et al. 2018). Em números absolutos, esses consumos são 5,7 x1066hh/mês e $163.000 \mathrm{kWh} / \mathrm{mês,}$ respectivamente. Na Universidade Federal do Estado de São Paulo (UNIFESP), dois câmpus de menor porte, São José dos Campos e Guarulhos, o consumo de energia elétrica variou em torno de 60.000 a $210.000 \mathrm{kWh} / \mathrm{ano}$, e 20.000 e $60.000 \mathrm{kWh} / \mathrm{ano}$, respectivamente, para o período compreendido entre 2014-2017 (UNIFESP, 2018). Nos estudos apresentados, os consumos de energia foram superiores ao da FUP (média de 20.207kWh/ano), sendo o câmpus da UNIFESP em Guarulhos o mais próximo (20.000 a $60.000 \mathrm{kWh} / \mathrm{ano})$.

O calendário acadêmico possui influência nos níveis de consumo de energia elétrica na FUP. A análise das contas de energia elétrica do ano de 2017 demonstrou que os meses com menor consumo são janeiro e agosto, com valores médios de $36.816 \mathrm{kWh}$. Nos demais meses, a média de consumo fica em $42.874 \mathrm{kWh}$. Apesar de os dois primeiros meses do ano corresponderem ao período das férias de verão, apenas o mês de janeiro tem menor consumo, que pode ser atribuído ao esvaziamento do câmpus e redução das atividades acadêmicas como um todo em função das férias de professores e alunos.

Na Figura 10, ao se relacionar o consumo de energia elétrica com a área total construída do câmpus, observa-se que entre os anos de 2007 e 2010 o $\mathrm{IC}_{\mathrm{EE}}$ ficou próximo a $3 \mathrm{kWh} / \mathrm{m}^{2}$.ano. Nesse período havia somente o prédio da UEP para abrigar todas as atividades executadas no câmpus. No ano de 2011, o prédio da UAC entrou em funcionamento, ocasionando uma redução no índice de consumo devido à expansão da área sem correspondência com aumento imediato de atividades. Os índices de consumo se mantiveram próximos $2 \mathrm{kWh} / \mathrm{m}^{2}$.ano até 2014. Após um período de adaptação à nova estrutura, de 2015 em diante, observou-se um aumento crescente no $\mathrm{IC}_{\mathrm{EE}}$, chegando a ultrapassar os $3 \mathrm{kWh} / \mathrm{m}^{2}$.ano em 2017. Entre os anos de 2015 e 2017, o consumo aumentou em 32\%.

De forma geral, desde 2013 o aumento do índice de consumo pode ser justificado pela gradativa ocupação dos espaços ainda livres nos prédios com a instalação de equipamentos para desenvolvimento das atividades de pesquisa, como fornos, estufas, geladeiras, freezers e aparelhos de ar-condicionado. Além disso, em 2015 o RU entrou em funcionamento, contribuindo com a demanda por energia elétrica.

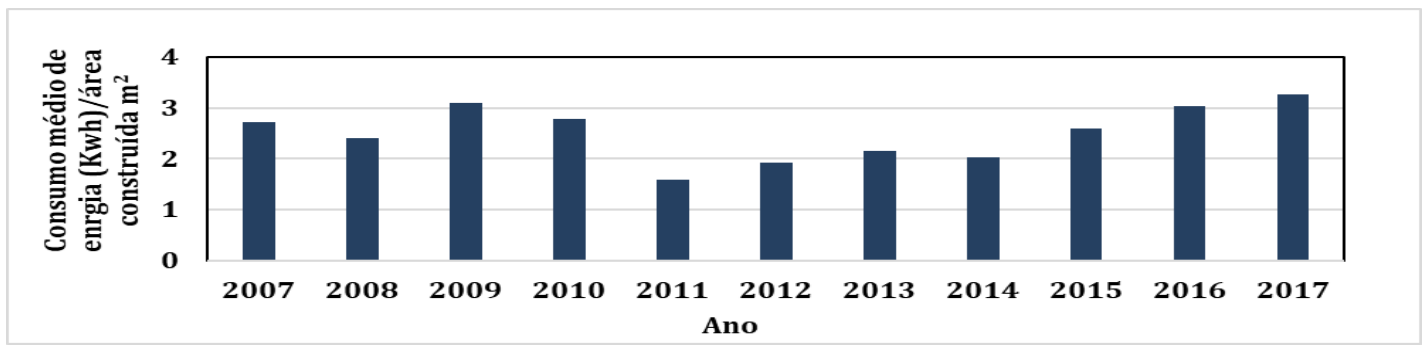

Figura 10 - Consumo anual por área construída da FUP. Fonte: autores (2019). 
Um estudo realizado por Zhou et al. (2013) apontou que a média nacional de consumo de energia elétrica em instituições de ensino superior na China era de $29,6 \mathrm{kWh} / \mathrm{m}^{2}$, enquanto nas universidades da província de Guangdong esse valor era de $30,61 \mathrm{kWh} / \mathrm{m}^{2}$, um pouco acima da média nacional para as mesmas tipologias de instalações. A universidade pública de Basque Country, na Espanha, é composta de 32 faculdades, divididas em quatro campi, com mais de 40.000 alunos e 7.500 trabalhadores. Nessa instituição, o consumo de energia pelos prédios acadêmicos varia significativamente, oscilando entre 18 e $107 \mathrm{kWh} / \mathrm{m}^{2}$, e o consumo com aquecimento varia entre 36.8 e $76 \mathrm{kWh} / \mathrm{m}^{2}$ (Irulegi et al. 2017).

Outro estudo, realizado por Chung \& Rhee (2014), avaliou o consumo de energia elétrica em 11 prédios de uma universidade localizada em Seul, Coreia do Sul. 0 consumo médio de energia dos edifícios pesquisados foi de $223 \mathrm{kWh} / \mathrm{m}^{2}$.ano. Apesar de os estudos apresentados terem sido realizados em universidades maiores, em área, do que a FUP, os dados demonstram que o consumo de energia em instituições de ensino está diretamente relacionado à área ocupada, atividades desenvolvidas e número de usuários e/ou frequentadores desses ambientes. Sendo assim, com a expansão da FUP, era de esperar um aumento do consumo de energia.

Através do levantamento de dados via inspeção de ambientes, foram obtidas informações preliminares sobre os sistemas de iluminação, ar-condicionado, equipamentos de escritório e outros mais relevantes quanto ao consumo, presentes no câmpus da FUP. Não foram contabilizadas lâmpadas, computadores e equipamentos raramente utilizados. Dentre os equipamentos verificados, os mais representativos em termos de consumo são os aparelhos de ar-condicionado (54 unidades); em termos de quantidade, os mais representativos são ventiladores ( 55 unidades), microscópio (25 unidades), lupa (25 unidades), geladeira (24 unidades), datashow (18 unidades) e freezer (13 unidades).

Atualmente, o sistema de iluminação dos ambientes da FUP utiliza apenas lâmpadas do tipo fluorescente, totalizando 4.223 unidades. Há uma proposta da UnB com a CEB em andamento para substituição das lâmpadas fluorescentes pelas de LED (Light Emitting Diode) e instalação de placas fotovoltaicas.

Outro problema diz respeito aos acionamentos dos sistemas de iluminação. Em vários ambientes do prédio da UEP, há apenas um interruptor para controlar o acionamento das luminárias, não permitindo um adequado aproveitamento da iluminação natural nem a iluminação de campos específicos. Por outro lado, no prédio das salas de aula, a maioria dos acionamentos são segmentados. Segundo Alvarez (1998), a segmentação do acionamento do sistema de iluminação pode ser considerada uma medida de baixo custo de implementação, quando realizada com materiais externos, apresentando um tempo de retorno bastante atraente.

Da análise do perfil de consumo de energia elétrica na FUP, constatou-se que é necessário um monitoramento através do uso de indicadores mais específicos, como fator de carga, usuário equivalente, dentre outros, de forma a identificar potenciais para redução do consumo, de forma a tornar a gestão de energia mais sustentável do câmpus.

De acordo com Crispim (2016) e Silva et al. (2017), grande parte das ações referentes à eficiência energética dizem respeito à mudança de comportamento dos usuários, e a utilização de programas com objetivo de mudar atitudes para combater o desperdício é fundamental. A adoção de programas para uso eficiente de energia elétrica justifica-se pela redução de consumo de energia que produz. Corroborando essa iniciativa, o Ministério do Planejamento e Gestão (MPOG) publicou em 2015 a Portaria 23, que em seu anexo I orienta as entidades públicas sobre as boas práticas de gestão e uso de água e energia elétrica.

Algumas universidades já estabeleceram programas para uso eficiente de energia elétrica. A Universidade de Tecnologia do Sul da China adotou o Sistema Supervisório de Economia de Energia no Câmpus e reduziu o consumo de energia em 25\%, se comparado à média nacional chinesa (Zhou et al. 2013). Na Universidade de São Paulo, Brasil, após quinze anos de implantação do Programa Permanente para Uso Eficiente de Energia Elétrica na Universidade de São Paulo (PURE-USP), o percentual de economia de energia também foi de $25 \%$ (Saidel et al. 2018). Uma economia de energia em torno de 5-15\% é em geral obtida rapidamente, com pouca ou nenhuma necessidade de capital quando um programa efetivo de gerenciamento de energia é implantado (Crispim, 2016). 


\section{Diagnóstico da área verde do câmpus}

O câmpus da FUP está instalado em ambiente de considerável fragilidade, já que se encontra inserido na área de amortecimento da Área de Preservação Ambiental do rio São Bartolomeu e dentro da sub-bacia do Ribeirão Mestre D'armas. Ademais, 40\% do terreno destinado ao campus encontra-se dentro da Área de Proteção de Manancial do Córrego Fumal, cuja demarcação aponta para sensibilidade dos recursos hídricos frente à ocupação das terras na região e para a proteção da captação de água para fins de abastecimento público (Holanda \& Gomes, 2010).

Sendo assim, o projeto do Plano Diretor e do Regimento da FUP, produzidos originalmente para viabilização inicial do câmpus (no momento, em revisão por comissão especial), prevê que o desenvolvimento do câmpus esteja pautado na sustentabilidade, considerando uma construção participativa. De acordo com Bizerril (2018), a FUP possui um maior potencial para o desenvolvimento de ações sustentáveis, dada a sua localização, cursos, estrutura organizacional e, ainda, perfil do corpo docente.

0 trabalho fitossociológico realizado nessa área em 2015 registrou um total de 1.084 indivíduos/ha e 60 espécies representativas de áreas preservadas de Cerrado sentido restrito encontrados em estudos realizados no Brasil Central e apresentando área basal total de $11,38 \mathrm{~m}^{2} \cdot \mathrm{ha}^{-1}$. A diversidade de Shannon $\left(\mathrm{H}^{`}\right)$ estimada foi 3,20, que é considerado alta e aponta para alta diversidade biológica do Cerrado sentido restrito na FUP. Ademais, espécies como Caryocar brasiliense (pequi) e Annona crassiflora (araticum), consideradas de alto valor para as atividades de extrativismo de produtos não madeireiros, foram encontradas na área, destacando a importância deste fragmento para a conservação da biodiversidade do bioma.

Nesse contexto, é essencial a conservação (manutenção com uso sustentável direto) ou até mesmo a preservação (uso indireto da biodiversidade e dos seus serviços ambientais) de parte desta paisagem. Do ponto de vista ecológico, tem-se conhecimento de que esta paisagem presta diferentes serviços ambientais, fundamentais para o bem-estar humano, como a manutenção da qualidade do solo e da água, o controle da temperatura do ar, o sequestro de carbono, entre outros.

Especificamente, retirar a cobertura vegetal de uma área evita que a água, que antes era amortecida pela vegetação, seja absorvida no solo e abasteça o lençol freático. A água agora pode escoar superficialmente, provocando erosão e acumulando-se nas partes mais baixas do terreno, acarretando problemas como enxurradas, alagamentos, enchentes e inundações. A rigor, a cobertura vegetal é a melhor proteção contra o escoamento superficial de água, em qualquer fitofisionomia. Assim sendo, modificações artificiais na cobertura vegetal, como aquelas decorrentes da implantação de sistemas urbanos próximos, podem produzir os mais variados impactos no meio ambiente.

Segundo Loboda \& De Angelis (2005), além do ponto de vista ecológico, a conservação e proteção dessas áreas constituem-se elementos imprescindíveis para o bem-estar do ser humano, pois influencia diretamente a saúde física e mental da população. Manter esta vegetação no local ainda proporciona funções educativas, tendo em vista que atualmente a área vem sendo utilizada para aulas de campo de diversas disciplinas, já que a vegetação proporciona sítios ideais de ensino e pesquisa para diversos cursos de graduação e pós-graduação. De maneira geral, professores e alunos da FUP têm se apropriado desse espaço para o desenvolvimento de atividades de ensino, pesquisa e extensão.

Com base no diagnóstico da área verde aqui apresentado, as estratégias dirigidas para o manejo sustentável desta área do câmpus podem, no futuro, ser orientadas para três zonas delimitadas: a) de preservação, ou seja, intocada, que representa $57,0 \%$ da área total; b) de conservação, área de uso sustentável direto, com 18,7\%; e c) aquelas destinadas às edificações, de modo que as futuras edificações sustentáveis sejam instaladas nas áreas mais degradadas do Cerrado sentido restrito, diminuindo assim a quantidade e a qualidade da vegetação a ser suprimida e, consequentemente, a diminuição do passivo ambiental devido pela Universidade, que representa 14,4\% (Figura 11). Atualmente, cerca de 9,9\% do Cerrado sentido restrito já foi eliminado para construção das edificações presentes no câmpus. 


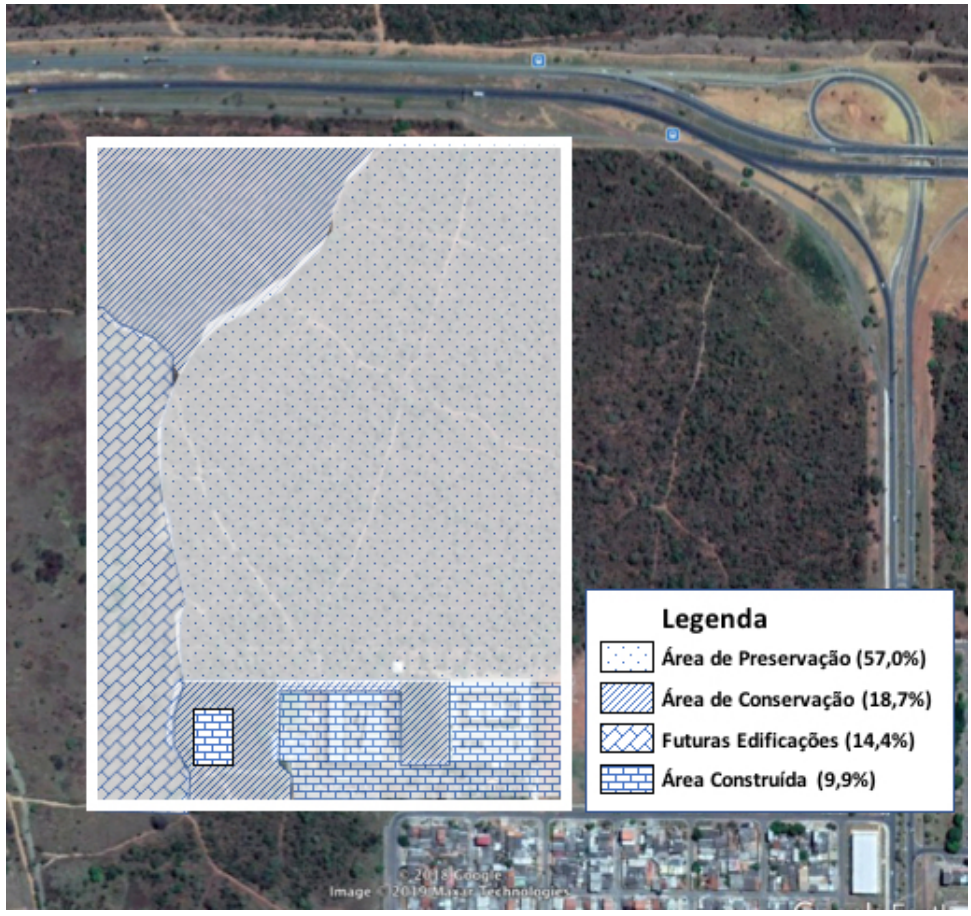

Figura 11 - Uso da terra identificados para o Câmpus da Faculdade UnB Planaltina (FUP) em Planaltina no Distrito Federal (15³5'51.09"S 47039'29.69"'O). Modificado de Couto-Júnior (2014). Fonte: Google Earth Pro (2019).

As questões relativas à conservação ambiental ocupam hoje significativa parcela dos investimentos e esforços de todos os segmentos da sociedade. Sendo assim, é importante promover o desenvolvimento em harmonia com o meio ambiente. No caso da FUP, Bizerril (2018) acredita que as ações de revisão do Plano Diretor e do Regimento da FUP envolvendo o ordenamento e a formalização de regras e missões para a condução do futuro do câmpus podem resultar em impactos significativos para fortalecer a prática da sustentabilidade realizadas através de processos participativos.

\section{Conclusões}

0 presente estudo permitiu identificar que, apesar do crescimento em área edificada e do número de estudantes e servidores da FUP desde o início do seu funcionamento em 2006, os consumos de água e energia também estão aumentando. Isso traz implicações ambientais, no contexto de escassez hídrica que o Distrito Federal enfrenta atualmente, e financeiras, principalmente no caso da tarifa de energia elétrica, que é mais cara que a de água.

Em relação aos resíduos sólidos, identificou-se que são produzidas aproximadamente 4 toneladas de resíduos por mês. 0 prédio do câmpus com maior geração de resíduos é o restaurante universitário, e a geração per capita de resíduos é de 92 gramas de resíduos/pessoa.dia. Em relação aos tipos de resíduos gerados no câmpus, esses são do tipo reciclável em sua maioria: $67 \%$. 0 estudo fitossociológico indicou alta diversidade biológica do Cerrado sentido restrito na FUP. Além disso, foram encontradas espécies com alto valor para as atividades de extrativismo de produtos não madeireiros, destacando a importância deste fragmento para a conservação da biodiversidade do bioma.

As informações obtidas neste trabalho são essenciais para delinear as estratégias a serem adotadas para tornar o câmpus mais sustentável, dentre elas a adoção de um programa para conservação de água, com busca por fontes alternativas de água, regulagem de equipamentos hidrossanitários, instalação de equipamentos economizadores e educação dos usuários.

Em relação aos resíduos sólidos, incentivo à não geração de resíduos, implantação de coleta seletiva com destinação da fração reciclável a cooperativas de reciclagem e compostagem da fração orgânica. 
Referente à energia elétrica, é necessário um monitoramento do consumo através do uso de indicadores mais específicos, como fator de carga, usuário equivalente, dentre outros, de forma a identificar potenciais para redução do consumo por meio da otimização do uso dos equipamentos, condições do ambiente e mudança de hábitos dos usuários.

Propõe-se ainda que as estratégias a serem adotadas para manutenção das áreas verdes envolvam a adoção de medidas de preservação, conservação, expansão do câmpus em áreas mais degradadas do Cerrado sentido restrito, para reduzir a supressão da cobertura vegetal, além da revisão do Plano Diretor e do Regimento da FUP, envolvendo o ordenamento e a formalização de regras e missões para a condução do futuro do câmpus. Por fim, a comunidade universitária deve ser desafiada a repensar e reconstruir suas políticas e práticas ambientais, a fim de contribuir para o desenvolvimento sustentável do câmpus da FUP.

\section{Agradecimentos}

Os autores agradecem ao Decanato de Extensão da UnB (DEX), à Prefeitura Universitária, à diretoria da FUP, ao assessor da diretoria Sr. Joaquim Oliveira, e também aos alunos extensionistas, bolsistas e voluntários que colaboraram para a realização deste trabalho.

\section{Referências}

Alvarez, A. L. M. (1998). Uso racional e eficiente de energia elétrica: metodologia para a determinação dos potenciais de conservação dos usos finais em instalações de ensino e similares (Dissertação de mestrado). Escola Politécnica, Universidade de São Paulo, São Paulo.

Bizerril, M. (2018). Universities in transition to sustainability: challenges and opportunities for the Campus of the University of Brasilia in Planaltina. In W. Leal Filho, F. Frankenberger, P. Iglecias \& R. Mülfarth (Org.), World sustainability series (pp. 361-370). Cham: Springer International Publishing.

Brasil. (2006, 25 de outubro). Decreto $n^{\circ}$ 5.940, de 25 de outubro de 2006. Dispõe sobre a separação dos resíduos recicláveis descartados pelos órgãos e entidades da administração pública federal direta e indireta, na fonte geradora, e a sua destinação às associações e cooperativas dos catadores de materiais recicláveis, e dá outras providências. Brasília: Diário Oficial da União, seção 1.

Brasil. (2010, 2 de agosto). Lei $n^{\circ}$ 12.305, de 02 de agosto de 2010. Institui a Política Nacional de Resíduos Sólidos; altera a Lei $n^{\circ}$ 9.605, de 12 de fevereiro de 1998; e dá outras providências. Brasília: Diário Oficial da União, seção 1.

Brasil. (2015, 12 de fevereiro). Portaria $n^{\circ} 23$, de 12 de fevereiro de 2015. Estabelece boas práticas e uso de Energia Elétrica e de Água nos órgãos e entidades da Administração Pública Federal direta, autárquica e fundacional e dispõe sobre o monitoramento de consumo desses bens e serviços. Brasília: Diário Oficial da União, seção 1.

Brett, L. M., Levy, R., \& Marans, W. (2012). Towards a campus culture of environmental sustainability: recommendations for a large university. International Journal of Sustainability in Higher Education, 13(4), 365-377. http://dx.doi.org/10.1108/14676371211262317.

Couto-Júnior, A. F. (2014). Relátorio Coordenação Estratégica Ambiental do Câmpus UnB Planaltina. Brasília: Universidade de Brasília.

Couto-Júnior, A. F. (2017). Relatório Câmpus UnB Planaltina. Brasília: Universidade de Brasília.

Crispim, I. M. M. (2016). Sustentabilidade Ambiental: com foco na eficiência energética da Universidade Federal de Goiás-Regional Catalão (Dissertação de mestrado). Universidade Federal de Goiás Regional Catalão, Catalão.

Chung, M. H., \& Rhee, E. K. (2014). Potencial opportunities for energy conservation in existing buildings on university campus: a field survey in Korea. Energy and Building, 78, 176-182.

http://dx.doi.org/10.1016/j.enbuild.2014.04.018. 
Fagnani, E. \& Guimarães, J. R. (2017). Waste management plan for higher education institutions in development countries: the continuous improvement cycle model. Journal of Cleaner Production, 147, 108-118. https://doi.org/10.1016/j.jclepro.2017.01.080.

Felfili, J. M., Silva, M. C., Jr., Rezende, A. V., Machado, J. W. B., Nogueira, P. E., \& Walter, S. M. T. (1994). Projeto biogeografia do bioma cerrado: vegetação e solos. Cadernos de Geociências, 12, 84-114.

Gallardo, A., Edo-Alcón, N., Carlos, M., \& Renau, M. (2016). The determination of waste generation and composition as an essential tool to improve the waste management plan of a university. Waste Management (New York, N.Y.), 53, 3-11. http://dx.doi.org/10.1016/j.wasman.2016.04.013. PMid:27107706.

Geng, Y., Liu, K., Xue, B., \& Fujita, T. (2013). Creating a 'green university' in China: a case of Shenyang University. Journal of Cleaner Production, 61, 13-19. http://dx.doi.org/10.1016/j.jclepro.2012.07.013.

Google Earth Pro. (2019). Faculdade UnB Planaltina, DF. Coordenadas 15o 35'53,99"S e 47o 39'30,01"O, Elevação 976 m. Recuperado em 23 agosto de 2019, de https://www.google.com.br/earth/download/gep/agree.html

Holanda, F., \& Gomes, V. (2010). Relatório do Plano Diretor para o Câmpus de Planaltina - Projeto Básico. Brasília: CEPLAN.

Instituto Brasileiro de Administração Municipal - IBAM. (2001). Manual de gerenciamento integrado de resíduos sólidos. Rio de Janeiro: IBAM.

Irulegi, O., Ruiz-Pardo, A., Serra, A., Salmerón, J. M., \& Veja, R. (2017). Retrofit strategies towards Net Zero Energy Educational Buildings: A case study at the University of the Basque Country. Energy and Building, 144, 387-400. http://dx.doi.org/10.1016/j.enbuild.2017.03.030.

Loboda, C. R., \& De Angelis, B. L. D. (2005). Áreas verdes públicas urbana: conceitos, usos e funções. Ambiência, 1(1), 125-139.

Lukman, R., Tiwary, A., \& Azapagic, A. (2009). Towards greening a university campus: the case of the University of Maribor, Slovenia. Resources, Conservation and Recycling, 53, 639-644.

http://dx.doi.org/10.1016/j.resconrec.2009.04.014.

Marinho, M., Gonçalves, M. S., \& Kiperstok, A. (2014). Water conservation as a tool to support sustainable practices in a Brazilian public university. Journal of Cleaner Production, 62, 98-106.

http://dx.doi.org/10.1016/j.jclepro.2013.06.053.

Menegassi, L. F. (2012). Avaliação da aplicabilidade de Indicadores de Consumo como ferramentas de auxílio à racionalização do uso de água do Câmpus Universitário Trindade (Trabalho de conclusão de curso). Centro Tecnológico, Universidade Federal de Santa Catarina, Florianópolis.

Mikulic, J., \& Babina, M. (2009). The role of universities in environmental management. Polish Journal of Environmental Studies, 18(4), 527-531.

Morales, M. R. (2012). Caracterización de residuos sólidos en la Universidad Iberoamericana, Ciudad de México. Revista Internacional de Contaminación Ambiental, 28(1), 93-97.

Okeniyi, J., \& Anwan, E. U. (2012). Solid wastes generation in Covenant University, Ota, Nigeria: characterization and implication for sustainable waste management. Journal of Materials and Environmental Science, 3(2), 419-425.

Petersen, J. E., Frantz, C. M., Shammin, M. R., Yanisch, T. M., Tincknell, E., \& Myers, N. (2015). Electricity and water conservation on college and university campuses in response to national competitions among dormitories: quantifying relationships between behavior. Conservation Strategies and Psychological Metrics, 10(12), 1-41. http://dx.doi.org/10.1371/journal.pone.0144070.

Saidel, M., Silva, R. S., \& Nascimento, L. M. (2018). The permanent program for efficient use of energy at university of São Paulo - PURE-USP. Management of Environmental Quality, 25(3), 361-372. http://dx.doi.org/10.1108/MEQ02-2014-0011. 
Santana, L. M. C., \& Kiperstok, A. (2010). Caracterização preliminar de consumo de água em prédios públicos administrativos. In Anais do I Congresso Baiano de Engenharia Sanitária e Ambiental (pp. 1-5). São Paulo: Acqua Consultoria.

Silva, R. D. S., Oliveira, R. C., \& Tostes, M. E. L. (2017). Analysis of the Brazilian energy efficiency program for electricity distribution systems. Energies, 10(9), 1391. http://dx.doi.org/10.3390/en10091391.

Sousa, W. C., Jr., Ribeiro, E. N., Oliveira, L. H., \& Ilha, M. S. O. (2011). O investimento em tecnologias poupadoras e o seu impacto no consumo de água em aeroportos. In W. C. Sousa Júnior \& E. N. Ribeiro (Eds.), Uso eficiente da água em aeroportos. São Carlos: Rima Editora.

Tangwanichagapong, S., Nitivattananon, V., Mohanty, B., \& Visvanathan, C. (2017). Greening of a campus through waste management initiatives. Experience from a higher education institution in Thailand. International Journal of Sustainability in Higher Education, 18(2), 203-217. http://dx.doi.org/10.1108/IJSHE-10-2015-0175.

Universidade Federal de São Paulo - UNIFESP. (2018). Gestão e segurança ambiental: consumo de água e energia elétrica. Recuperado em 10 de agosto de 2018, de http://www.unifesp.br/reitoria/dga/dga-campi/consumo-deagua-e-energia

Vagnoni, E. E., \& Cavicchi, C. (2015). An exploratory study of sustainable development at Italian Universities. International Journal of Sustainability in Higher Education, 16(2), 217-236. http://dx.doi.org/10.1108/IJSHE-032013-0028.

Vega, C. A., Benítez, S. O., \& Barreto, M. E. R. (2008). Solid waste characterization and recycling potential for a univeristy campus. Waste Management (New York, N.Y.), 28(Suppl 1), S21-S26.

http://dx.doi.org/10.1016/j.wasman.2008.03.022. PMid:18572396.

Zhang, N., Williams, I. D., Kemp, S., \& Smith, N. F. (2011). Greening academia: developing sustainable waste management at Higher Education Institutions. Waste Management (New York, N.Y.), 31(7), 1606-1616. http://dx.doi.org/10.1016/j.wasman.2011.03.006. PMid:21450452.

Zhao, W., \& Zou, Y. (2015). Green university initiatives in China: a case of Tsinghua University. International Journal of Sustainability in Higher Education, 16(4), 491-506. http://dx.doi.org/10.1108/IJSHE-02-2014-0021.

Zhou, X., Yan, J., Zhu, J., \& Cai, P. (2013). Survey of energy consumption and energy conservation measures for colleges and universities in Guandong province. Energy and Building, 66, 112-118.

http://dx.doi.org/10.1016/j.enbuild.2013.07.055.

Editores: Janaina Camile Pasqual Lofhagen e Christopher Hawkins.

Recebido: Mar. 17, 2019

Aprovado: Mar. 24, 2019 